\title{
Erratum to: Analysing the content of the European Ocean Biogeographic Information System (EurOBIS): available data, limitations, prospects and a look at the future
}

\author{
Leen Vandepitte $\cdot$ Francisco Hernandez • \\ Simon Claus · Bart Vanhoorne $\cdot$ Nathalie De Hauwere \\ Klaas Deneudt $\cdot$ Ward Appeltans $\cdot$ Jan Mees
}

Published online: 27 April 2011

(C) Springer Science+Business Media B.V. 2011

\section{Erratum to: Hydrobiologia (2011) 667:1-14 DOI 10.1007/s10750-011-0656-x}

In the above mentioned publication, an incorrect version of Fig. 1a has been used. Due to accidental switching of the dates of the data contributions of two large data providers, the previously published Fig. 1a gives an erroneous indication of the growth of EurOBIS - expressed in number of available distribution records over time-in the central part of the graph. This error has been rectified in the revised graph published on the following page, now representing the correct increase in number of distribution records for EurOBIS. 
Fig. 1 Number of distribution records available in EurOBIS in June 2010. (a) Evolution in growth of number of distribution records since the start of EurOBIS until June 2010

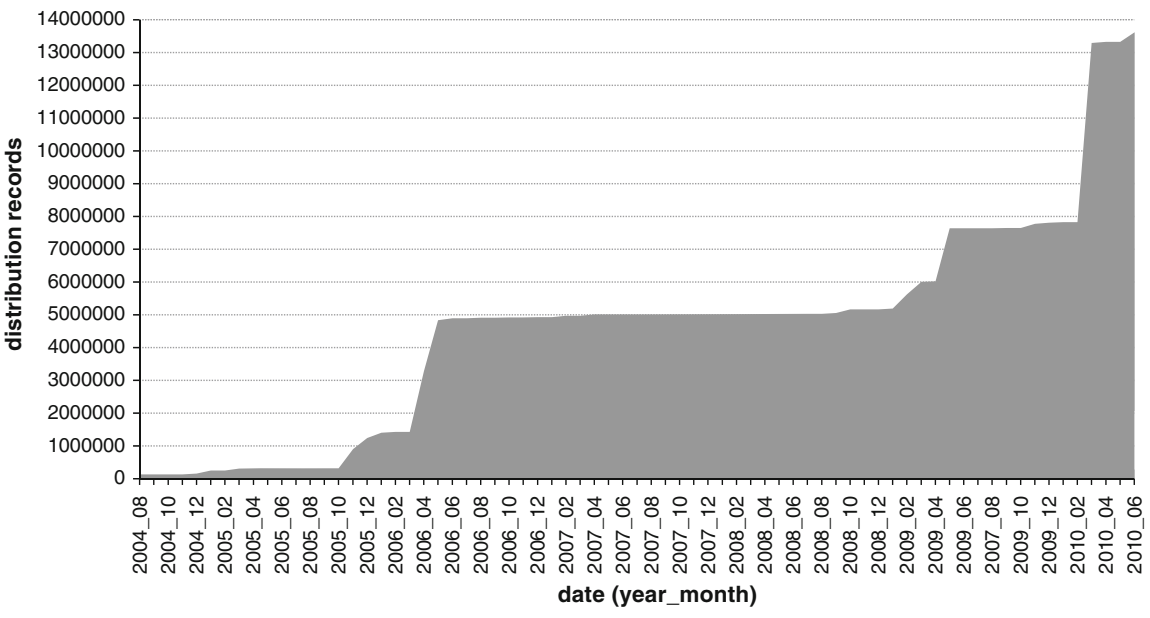

